\title{
Projecting the Impact of Nutrition Policy to Improve Child Stunting: A Case Study in Guatemala Using the Lives Saved Tool
}

\author{
Scott Tschida, a Ana Cordon, ${ }^{a}$ Gabriela Asturias, ${ }^{b}$ Mónica Mazariegos, ${ }^{c}$ María F. Kroker-Lobos, ${ }^{c}$ \\ Bianca Jackson, ${ }^{d}$ Peter Rohloff, a,e David Flood ${ }^{a, f}$
}

\section{Key Finding}

- Scaling-up coverage of evidence-based nutrition interventions recommended by the international community would only lead to a small improvement in child stunting in Guatemala and are unlikely to meet the ambitious national goals set for 2024 or the 2030 SDGs.

- Our results support an increased focus on strategies that address the social determinants that contribute to stunting rather than a narrow focus on nutritionspecific interventions.

\section{Key Implications}

- Large improvements in child stunting in some highburden countries like Guatemala are unlikely to be achieved solely based on increases in nutrition intervention coverage.

- Multisectoral nutritional and social policies are needed to address the structural drivers of stunting.

a Center for Research in Indigenous Health, Wuqu' Kawoq, Tecpán, Chimaltenango, Guatemala.

${ }^{b}$ Centre for Evidence-Based Development, Fundación Desarrolla Guatemala para la Educación y Salud (FUNDEGUA), Guatemala City, Guatemala.

'INCAP Research Center for the Prevention of Chronic Diseases (CIIPEC), Institute of Nutrition of Central America and Panama (INCAP), Calzada Roosevelt, Guatemala City, Guatemala.

${ }^{d}$ Center for American Indian Health, Johns Hopkins Bloomberg School of Public Health, Baltimore, MD, USA.

'Division of Global Health Equity, Brigham and Women's Hospital, Boston, MA, USA

fDepartment of Internal Medicine, National Clinician Scholars Program, University of Michigan, Ann Arbor, MI, USA.

Correspondence to Scott Tschida (scott.tschida@wuqukawoq.org).
Resumen en español al final del artículo.

\section{ABSTRACT}

Background: Child stunting is a critical global health issue. Guatemala has one of the world's highest levels of stunting despite the sustained commitment to international nutrition policy best practices endorsed by the Scaling Up Nutrition (SUN) movement. Our objective was to use Guatemala as a case study to project the impact of a recently published national nutrition policy, the Great Crusade, that is consistent with SUN principles.

Methods: We used the Lives Saved Tool (LiST) to project the impact of scaling-up of nutrition interventions proposed in the Great Crusade and recommended by SUN. Our outcomes were changes in stunting prevalence, number of stunting cases averted, and number of cases averted by intervention in children under 5 years of age from 2020 to 2030 . We considered 4 scenarios: (1) intervention coverage continues based on historical trends, (2) coverage targets in the Great Crusade are achieved, (3) coverage targets in the Great Crusade are achieved with reduced fertility risk, and (4) coverage reaches an aspirational level.

Results: All scenarios led to modest reductions in stunting prevalence. In 2024, stunting prevalence was estimated to change by $-0.1 \%(95 \%$ confidence interval $[\mathrm{Cl}]=0.0 \%,-0.2 \%)$ if historical trends continue, $-1.1 \%(95 \% \mathrm{Cl}=-0.8 \%,-1.5 \%)$ in the Great Crusade scenario, and $-2.2 \%(95 \% \mathrm{Cl}=-1.6 \%,-3.0 \%)$ in the aspirational scenario. In 2030, we projected a stunting prevalence of $-0.4 \%(95 \% \mathrm{Cl}=-0.2 \%,-0.8 \%)$ and $-3.7 \%(95 \% \mathrm{Cl}=-2.8 \%$, $-5.1 \%)$ in the historical trends and aspirational scenario, respectively. Complementary feeding, sanitation, and breasffeeding were the highest-impact interventions across models.

Conclusions: Targeted reductions in child stunting prevalence in Guatemala are unlikely to be achieved solely based on increases in intervention coverage. Our results show the limitations of current paradigms recommended by the international nutrition community. Policies and strategies are needed to address the broader structural drivers of stunting.

\section{BACKGROUND}

M ore than 149 million children under 5 years of age worldwide have inadequate linear growth, which is also referred to as child stunting. ${ }^{1}$ Stunting is a crucial global child health issue given its negative impacts on health and well-being throughout the lifespan. In 
the short term, stunted children are more likely to experience morbidity, mortality, and developmental delays. ${ }^{2}$ In the long term, adults who were stunted as children are at risk for lower cognitive performance, educational achievement, and economic productivity. ${ }^{3-5}$ Stunting also may contribute to the development of adult cardiometabolic conditions such as diabetes, obesity, and hypertension. ${ }^{6,7}$ Sustainable Development Goal (SDG) target 2.2 aims to reduce the number of stunted children by $40 \%$ by 2025 and to eliminate all forms of malnutrition by 2030 .

In response to the increasing recognition of malnutrition as a problem of global importance, the Scaling Up Nutrition (SUN) movement was founded in September $2010 .^{8}$ The SUN movement works to end all forms of malnutrition by facilitating coordination between local, regional, and international stakeholders. ${ }^{8}$ More than 60 countries have joined the SUN movement by establishing national organizations of nutrition stakeholders that are supported by a high-level individual in the government. ${ }^{9}$ Increasing the coverage of evidence-based nutrition interventions is a central focus of the SUN agenda for improving nutrition in member countries. These interventions are targeted during the "first 1,000 days." This period of time refers to the critical period of growth and development that occurs between conception and a child's second birthday.

The current study examines child nutrition policy in Guatemala, a Central American country of 16.9 million people. In 2005, Guatemala ratified the National Food and Nutrition Security System (SINASAN in Spanish), establishing a legal framework and political commitment to address stunting. ${ }^{10}$ In 2010, Guatemala joined the SUN movement, affirming many of its previous commitments while incorporating SUN principles into its subsequent national nutrition plans. ${ }^{11-13}$ In 2015, the SUN movement singled out Guatemala as a model case of a country that had made significant progress on addressing nutrition. ${ }^{14}$ In 2017, Guatemala was ranked number 1 of 45 countries in its political commitment to nutrition in the Hunger and Nutrition Commitment Index. ${ }^{15}$ However, despite more than a decade of political commitment to nutrition, Guatemala still has one of the world's highest levels of stunting. ${ }^{2,16}$ Overall, $47 \%$ of Guatemalan children under the age of 5 years are stunted. ${ }^{17}$ Within Guatemala, there are marked disparities in stunting according to wealth status, educational level, and ethnicity that have not substantially improved in the last 2 decades. ${ }^{16,18}$ Nearly $70 \%$ of poor indigenous children in Guatemala are stunted. ${ }^{19}$
In February 2020, the new Guatemalan government led by President Alejandro Giammattei released the most recent national nutrition policy, the Gran Cruzada Nacional por la Nutrición ("Great National Crusade for Nutrition," henceforth "Great Crusade"). ${ }^{13}$ Like previous national nutrition policies that were influenced by the SUN framework, the Great Crusade focuses on evidence-based interventions delivered during the 1,000-day window. ${ }^{11,12}$ Interventions in the Great Crusade include both nutrition-specific and nutrition-sensitive interventions. Nutrition-specific interventions address the immediate determinants of stunting through micronutrient supplementation, breastfeeding promotion, complementary feeding, and other strategies. ${ }^{20}$ Nutrition-sensitive interventions address the structural underpinnings of chronic malnutrition by targeting poverty, education, women's empowerment, environmental protection, social safety nets, and other targets. ${ }^{21}$ One of the Great Crusade's principal goals is to reduce the prevalence of child stunting by $7 \%$ by $2024 .^{13}$

However, it is uncertain if the Great Crusade can reach this ambitious goal. Previous national policies have not met stunting prevalence targets. ${ }^{22}$ Nutrition-specific interventions form the backbone of the Great Crusade's recommendations, but these interventions tend to have small effect sizes on stunting in clinical trials. ${ }^{23}$ Nutrition-sensitive interventions put forth by the Great Crusade, while promising, have limited evidence of benefit on child growth. ${ }^{21}$ Finally, implementation of nutrition interventions in Guatemala historically has been inconsistent, which may limit the impact of national policies. ${ }^{24}$

The objective of our study was to project the impact of the 2020 Guatemalan national nutrition policy, the Great Crusade. We used a popular maternal and child health modeling program, the Lives Saved Tool (LiST), to carry out our projections. Realistic projections can show the potential impact and uncertainties of nutrition policy in Guatemala and assist in the policy's implementation. Finally, as a case study in the real-time application of a policy modeling tool, this study may assist policymakers in other low- and middleincome countries who wish to project the impact and uncertainty of maternal and child health policies in their own countries.

\section{METHODS}

This modeling study used observational data and LiST to project the policy impact of the Great Crusade. LiST is a publicly available maternal and
Despite more than a decade of political commitment to nutrition, Guatemala still has one of the world's highest levels of stunting. 
child health modeling tool within the Spectrum software package version 5.761 (Avenir Health). Previous publications have detailed LiST's methodology. ${ }^{25-28}$ LiST is a linear and deterministic model that uses publicly available data to project maternal and child outcomes including stunting. ${ }^{29,30}$ Although not a probabilistic model, LiST contains an uncertainty analysis. LiST can assess uncertainty by randomly sampling distributions around the model's inputs. ${ }^{31}$ We used LiST's uncertainty analysis tool by running 250 iterations with plausibility bounds set to $95 \%$. Our projections are included in a Supplement. LiST was developed in 2003 and is maintained by the Johns Hopkins Bloomberg School of Public Health with funding from the Bill and Melinda Gates Foundation. $^{25}$ Since its development, LiST has been used in more than 110 peer-reviewed research publications. ${ }^{32}$ Many LiST publications have been seminal contributions in the field of global maternal and child health such as Disease Control Priorities 3rd Edition ${ }^{33}$ and the 2008 and the 2013 Lancet Maternal and Child Undernutrition Series papers. ${ }^{23}$

\section{Data Sources}

Data inputs necessary to project stunting in LiST cover 4 broad categories: (1) demographics, (2) baseline child and maternal health characteristics, (3) intervention coverage levels, and (4) intervention effectiveness.

National-level default input data for most countries including Guatemala are available for download through Spectrum. The default data sources include demographic surveys, academic research, and estimates produced by international bodies such as the World Health Organization (WHO), United Nations Children's Fund (UNICEF), United Nations Population Fund (UNFPA), World Bank, and United Nations. Default data are updated either annually or as often as national surveys are released. ${ }^{34}$

We carefully reviewed each default input for Guatemala, and, using our knowledge of local data sources, updated inputs with more recent or appropriate values. With one exception, data on intervention effectiveness were not changed from the default values estimated from systematic reviews, metaanalyses, Delphi methods, and randomized control trials. ${ }^{34}$ In May 2020, after consulting with a member of the LiST team at the Johns Hopkins Bloomberg School of Public Health, we were informed of new intervention effectiveness estimates for water, sanitation, and hygiene (WASH) interventions. We then manually updated these estimates in the model. A complete list of data sources and input parameters used in this study can be found in the Supplement.

\section{Outcomes}

We defined policy impact through our primary outcomes of changes in stunting prevalence, number of stunting cases averted, and number of stunting cases averted by intervention. Stunting is defined in LiST as children with a height-for-age that is 2 standard deviations or more below the median of the WHO Child Growth Standards. ${ }^{35}$

\section{Intervention Variables}

We first reviewed the interventions that impact child stunting in LiST and cross-referenced them with the interventions recommended in the Great Crusade. Of the 15 stunting-related interventions included in LiST, 14 were proposed in the Great Crusade. We subsequently excluded 2 interventions described in the Great Crusade that are not epidemiologically significant in Guatemala and 2 additional interventions for which data were not available. Our final model included 10 interventions (Table and Supplement). Of note, the Great Crusade includes interventions, such as education and conditional-cash transfer programs, that are not included in LisT because there is no high-level evidence that they are effective.

\section{Scenarios}

We modeled 4 scenarios of intervention coverage change from 2020 to 2030 . We chose this period because it encompasses both the Great Crusade's targets in 2024 as well as the SDG targets in 2030. Each scenario started with the same inputs for the baseline year of 2020 and continued over time based upon the below assumptions. Baseline, 2024, and 2030 coverage levels can be found in the Supplement.

\section{Scenario 1: Historical Trends}

Our baseline scenario estimated future coverage levels based on past historical trends. As described below and similar to prior LiST analyses, ${ }^{36}$ we estimated future trends in intervention coverage based on regression models of historical survey data. The key assumption of this scenario is that past intervention coverage trends predict future coverage.

\section{Scenario 2: Great Crusade}

Intervention coverage levels were set to the goals detailed in the Great Crusade. ${ }^{13}$ From 2024 to 2030, coverage levels remained static. 
TABLE. Stunting-Related Interventions Included in the Models

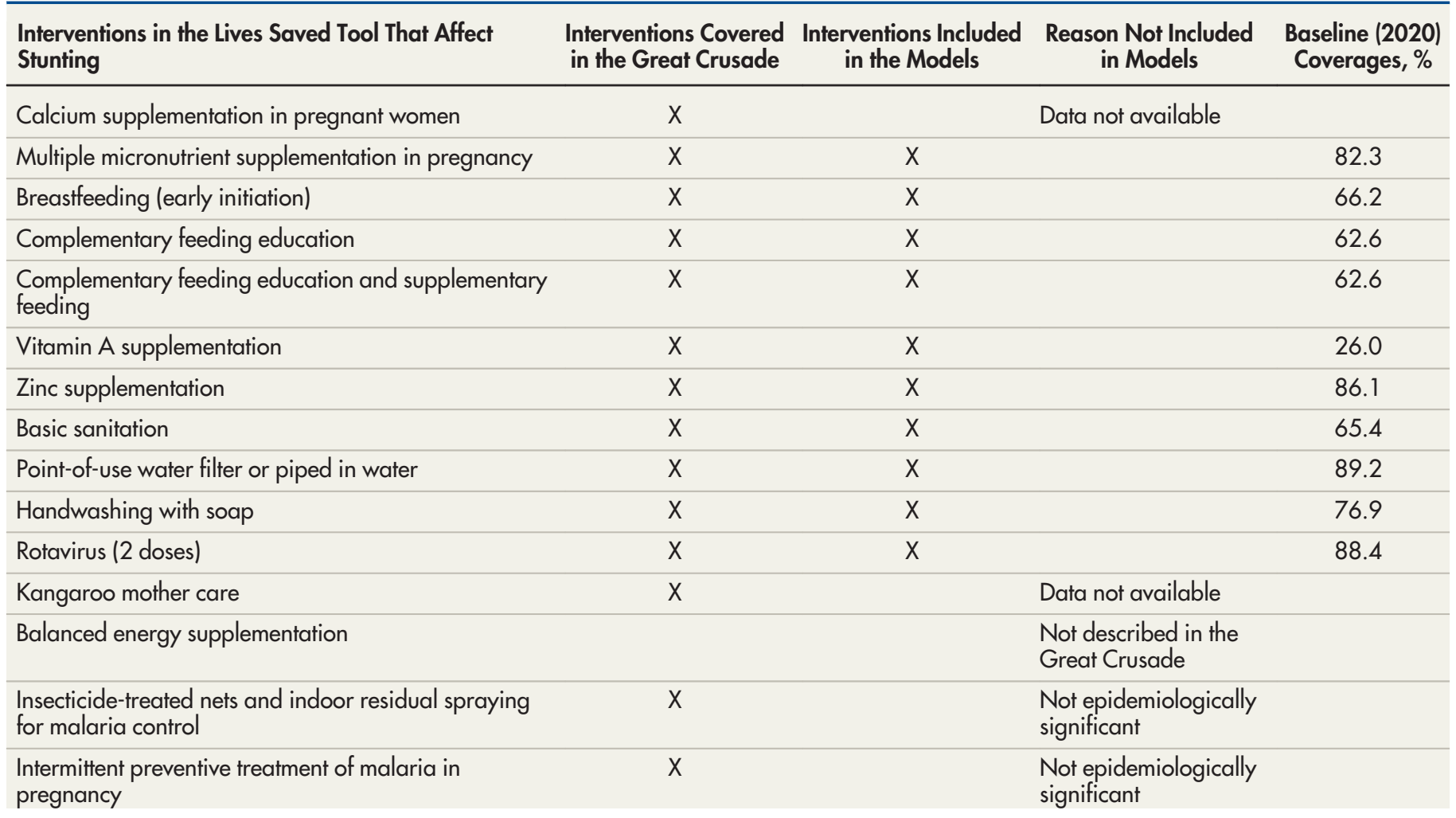

\section{Scenario 3: Great Crusade With Decreased Fertility Risk}

Intervention coverage levels were set to the goals detailed in the Great Crusade. Fertility risk was lowered by eliminating pregnancies before 18 years of age and birth intervals of less than 24 months by 2030. This scenario assumed a hypothetical implementation of policies and interventions to eliminate teen pregnancy and short interpregnancy intervals. These measures have been associated with improved child stunting in international and national surveys but were not otherwise included as an intervention in the models. ${ }^{37,38}$

\section{Scenario 4: Aspirational Coverage}

Intervention coverage levels were set to reach $90 \%$ by 2024 . From 2024 to 2030 , coverage levels remained static.

\section{Analyses \\ Data Preparation}

Given that the majority of survey data available in Guatemala were at least 3 years old, we updated model input parameters for the baseline year of
2020. We estimated baseline levels by fitting a logistic regression curve fixed to pass through the last available data point of population-averaged survey data. Shifting the trendline in this manner has been done in a prior LiST study and reflects our greater confidence in more recent survey estimates in Guatemala. ${ }^{36}$ Stata version 16.1 was used in these analyses.

Consistent with previous LiST studies, increases in intervention coverage over time were assumed to increase linearly from the base year. ${ }^{39,40}$ In instances in which coverage inputs exceeded $90 \%$, we fixed values at $90 \%$ for the remaining years to reflect a reasonable upper bound for coverage. We did not fix the upper bound of WASH interventions, as we believe that these interventions will follow a meaningful trend of improvement beyond this level.

Consistent with previous LiST studies, increases in intervention coverage over time were assumed to increase linearly from the base year. ${ }^{39,40}$ In instances where coverage inputs exceeded $90 \%$, we fixed values at $90 \%$ for the remaining years to reflect a reasonable upper bound for coverage. We did not fix the upper bound of WASH interventions, as we 
believe that these interventions will follow a meaningful trend of improvement beyond this level.

\section{Ethics and Preregistration}

This study uses de-identified data and did not require approval by the Institutional Review Board of the University of Michigan (UM00177760). We preregistered our analysis at the Open Science Foundation on April 13, 2020. ${ }^{41}$

\section{RESULTS}

\section{Changes in Stunting Prevalence}

The projected impact of scaling up intervention coverage for each scenario is depicted in Figure 1. The shaded area represents $95 \%$ confidence intervals (CIs), which for the Great Crusade (fertility) model are omitted to simplify the figure given overlapping uncertainty bands.

\section{0-2024 Outcomes}

If intervention coverage levels increase at historical levels stunting prevalence is projected to change in 2024 by $-0.1 \%$ ( $95 \% \mathrm{CI}=0.0 \%,-0.2 \%)$. The projected change in stunting prevalence in the Great Crusade model by 2024 is a $-1.1 \%(95 \%$ CI= $-0.8 \%,-1.5 \%)$ change. The projected change in stunting prevalence in the Great Crusade with reduced fertility risk model is nearly identical at $-1.1 \%(95 \% \mathrm{CI}=-0.8 \%,-1.6 \%)$. Our aspirational model projects a $-2.2 \%(95 \% \mathrm{CI}=-1.6 \%,-3.0 \%)$ change in stunting prevalence by 2024 .

\section{0-2030 Outcomes}

In the Great Crusade model that assumes coverage goals are attained in 2024 and then maintained from 2024 to 2030, the model projected a change in the prevalence of stunting of $-1.8 \%(95 \% \mathrm{CI}=$ $-1.4 \%,-2.6 \%)$. The historical trends and aspirational scenarios projected a change in stunting from 2020 to 2030 of $-0.4 \%(95 \% \mathrm{CI}=-0.2 \%,-0.8 \%)$

Increased
intervention
coverage as
proposed in the
Great Crusade are
unlikely to
improve child
stunting outcomes
enough to meet
2024 national
targets or
2030 SDG targets.
and $-3.7 \%(95 \% \mathrm{CI}=-2.8 \%,-5.1 \%)$, respectively.

\section{Stunting Cases Averted in 2024 and 2030}

Figure 2 shows the estimated number of stunted cases that would be averted by scenario per year. The shaded area represents $95 \%$ CIs, which for the Great Crusade (fertility) model are omitted to simplify the figure given overlapping uncertainty bands.

\section{0-2024 Outcomes}

The estimated number of cumulative stunting cases averted in the historical trends model from
2020 to 2024 is 4,463 . The Great Crusade is projected to avert 42,754 total cases from 2020 to 2024, and implementation of the Great Crusade along with decreasing fertility risk would avert 43,208 total cases over this period. The aspirational model is estimated to avert 83,970 total cases of stunting from 2020 to 2024.

\section{0-2030 Outcomes}

From 2020 to 2030, if intervention coverage continues to rise based on historical trends, we have estimated that 29,307 total cases of stunting will be averted. The Great Crusade plan is projected to avert 215,033 total cases during this time, and the Great Crusade model along with decreasing fertility risk would avert 219,167 total cases. The aspirational model is estimated to avert 437,958 total cases of stunting from 2020 to 2030.

\section{Stunting Cases Averted by Intervention}

Figure 3 elaborates the contribution of each intervention to the cumulative number of stunting cases averted from 2020 to 2024 (panel A) and from 2020 to 2030 (panel B). In the historical trends model, changes in coverage of point-ofuse water filter or piped water primarily contribute to the number of stunting cases averted. Differences in stunting cases averted between the historical trends and the Great Crusade models are driven largely by differential coverage of complementary feeding and sanitation. Differences between the Great Crusade models and aspirational model are largely driven by differential coverage in complementary feeding and breastfeeding promotion.

Figure 4 shows the cumulative contribution of each intervention on stunting cases averted in the aspirational model from 2020 to 2030 . This model projected that $56 \%(245,129$ of 437,579$)$ of averted stunting cases would be attributable to increasing coverage of complementary feeding.

We include the complete output data of our models in the Supplement.

\section{DISCUSSION}

This study used LiST to project the impact of the 2020 Guatemalan national nutrition policy, the Great Crusade. We found that increases in intervention coverage proposed in the Great Crusade are unlikely to improve child stunting outcomes to a sufficient degree to meet 2024 national targets or 2030 SDG targets. We also described the uncertainty of our projections and the relative impact of different interventions. Our study has implications for 
FIGURE 1. Projected Change in Stunting Prevalence in Children Under 5 Years From the Baseline Year by Scenario

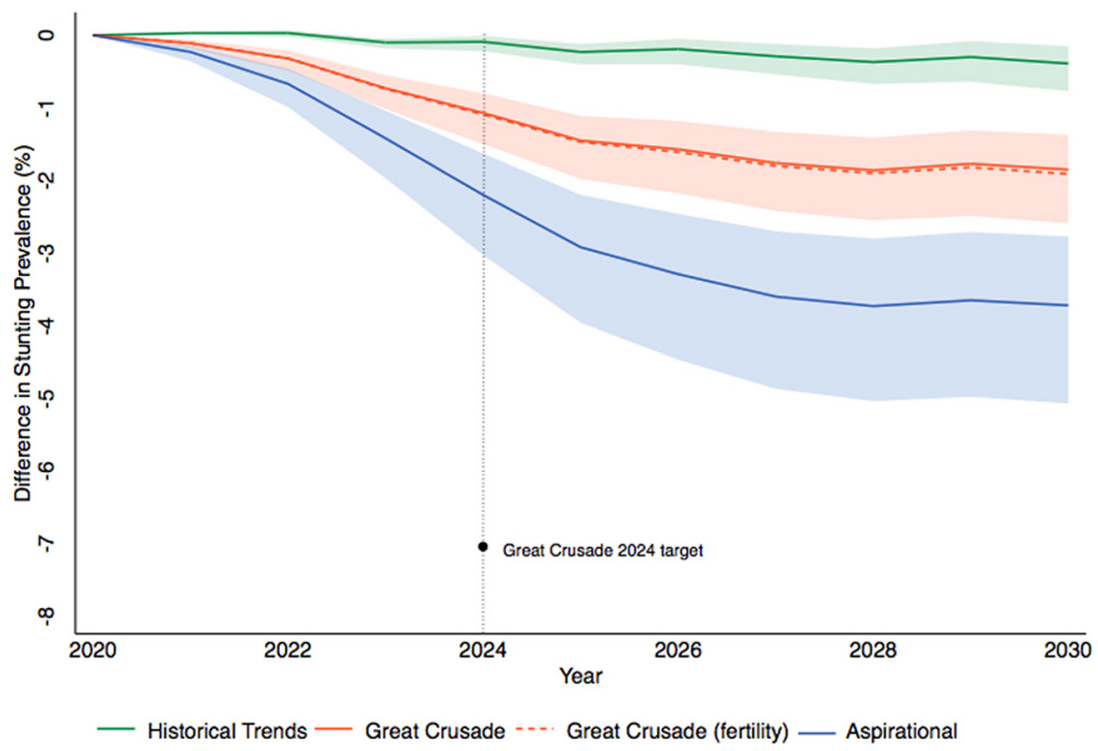

FIGURE 2. Projected Number of Stunting Cases Averted in Children Under 5 Years per Year From the Baseline Year by Scenario

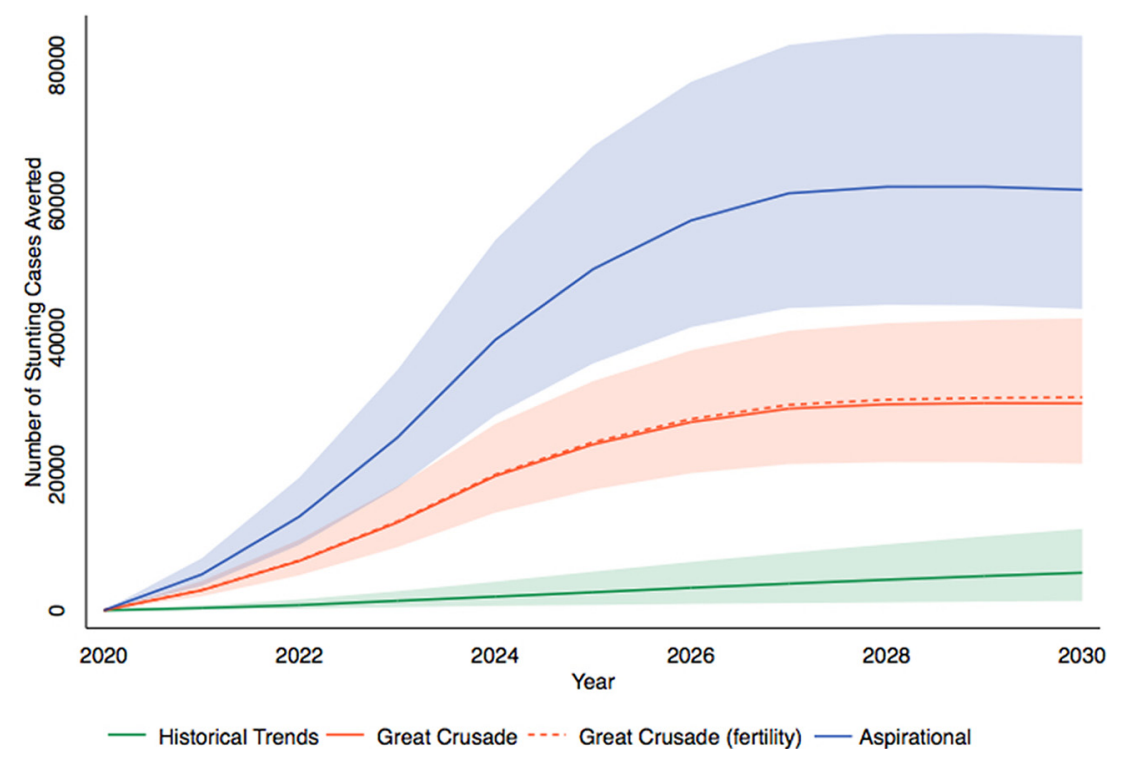

the optimization of nutrition in Guatemala and other low- and middle-income countries.

Our modeling study of nutrition policy in Guatemala reveals limitations in the SUN framework that focuses on scaling up evidence-based nutrition interventions. Despite strong political commitment to the SUN movement since 2010, Guatemala has not met historical stunting targets and, as our study 
FIGURE 3. Contribution of Interventions on Cumulative Stunting Cases Averted by Scenario (A) 2020-2024 (B) $2020-2030^{\circ}$
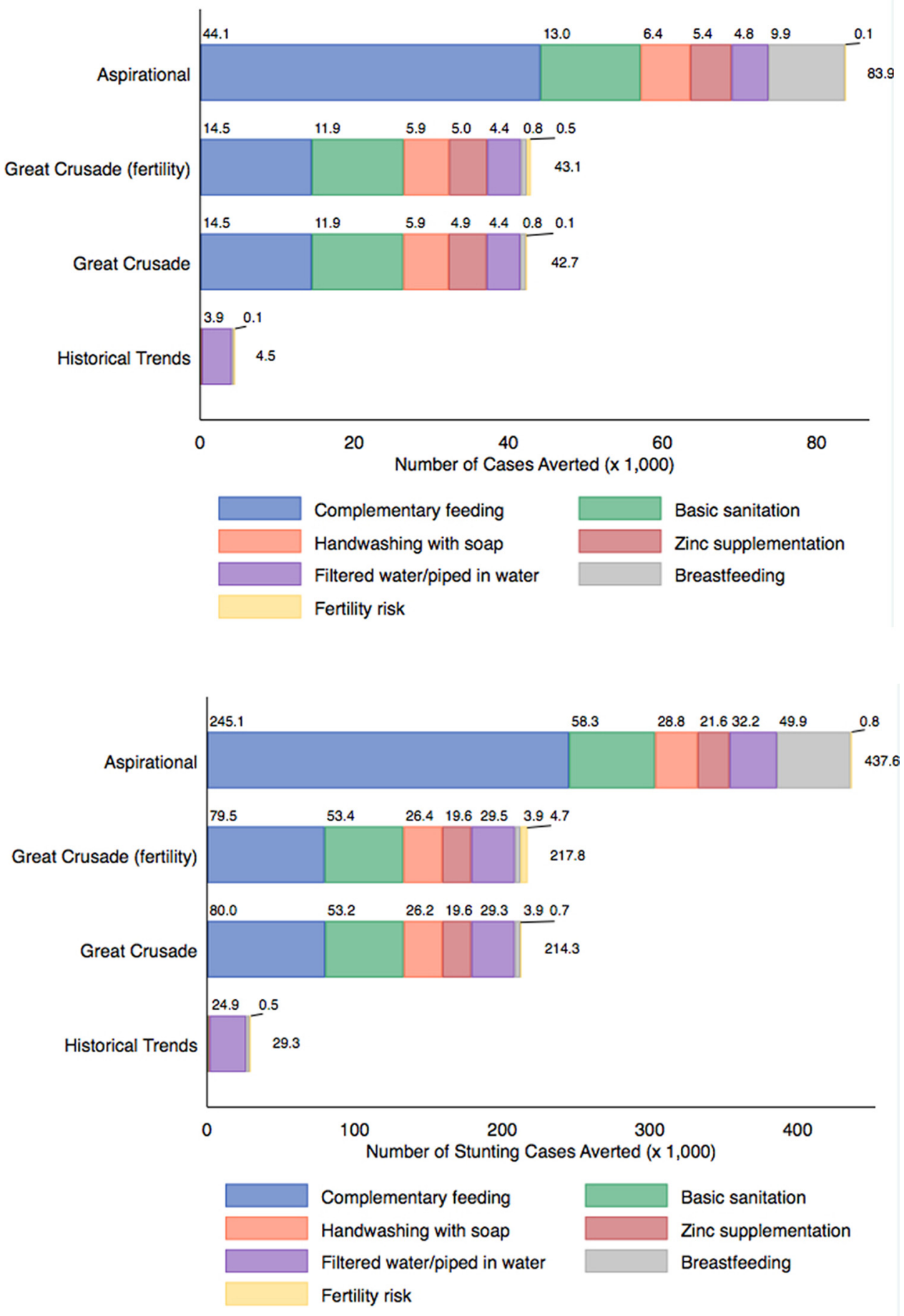

a Only interventions that contribute at least $1.0 \%$ of the total are included in colored subsegments. 
FIGURE 4. Contribution of Interventions on Cumulative Stunting Cases Averted in the Aspirational Model ${ }^{a}$

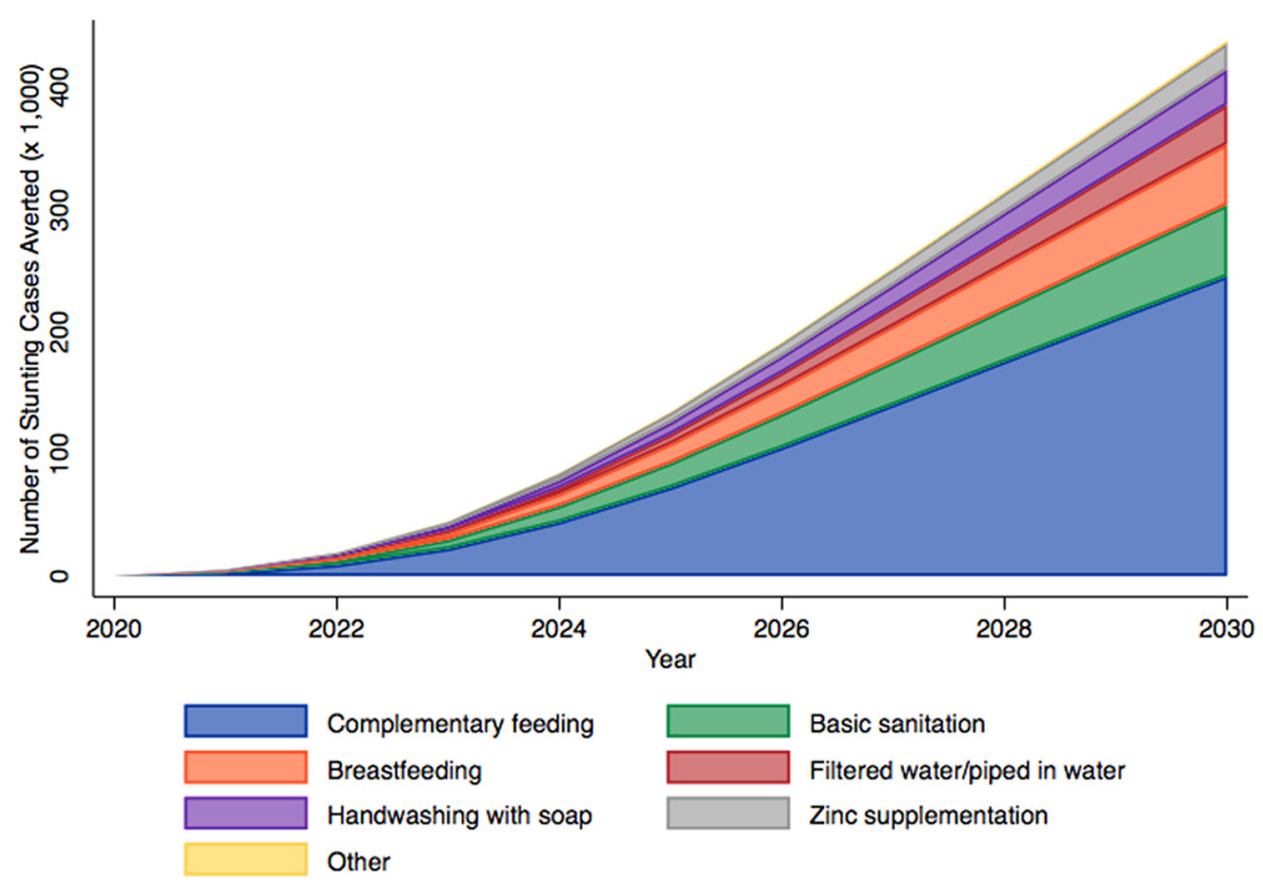

a "Other" category includes multiple micronutrient supplementation, fertility risk, and rotavirus vaccination.

shows, may have difficulty meeting future goals. In the 2013 Lancet series on Maternal and Child Health, it was estimated that increasing the coverage of 10 evidence-based interventions to $90 \%$ in 34 high-burden countries would result in a $20 \%$ relative reduction in stunting prevalence. ${ }^{23}$ Our models suggest that increasing intervention coverage to $90 \%$ in Guatemala would result in a $4.7 \%$ relative reduction in stunting in 2024 and $8.0 \%$ relative reduction in 2030. The modest impact of nutrition coverage expansion in Guatemala compared with other countries may be explained by the relatively high baseline intervention coverage in Guatemala. Taken together, our findings imply that there may be substantial heterogeneity in impact between countries that implement evidence-based nutrition stunting interventions endorsed within the SUN framework. In other country case studies, contextual differences and variations in investments both within and outside the health sector have been proposed as explanatory factors for improvements in stunting. ${ }^{42}$

Our findings also reveal the limitations of currently available evidence to prevent stunting. Except for WASH, all the stunting interventions incorporated in LiST and included in our models are nutrition-specific interventions. These interventions are supported by high-level evidence, but their effect sizes are generally modest. As an example, complementary food supplementation in food-insecure populations causes a $0.10(95 \% \mathrm{CI}=0.03,0.17) \mathrm{im}$ provement in length-for-age Z-scores. ${ }^{43}$ Nutritionsensitive interventions focusing on the broader context of nutrition including poverty, agriculture, social safety nets, education, and other areas have been proposed as a potential way to generate more sizeable reductions in stunting. ${ }^{44,45}$ In Peru, for example, large improvements in child stunting observed from 2000 to 2013 were likely attributable to economic growth, increased societal participation, poverty-reduction strategies, and increased health spending. ${ }^{46,47}$ Furthermore, a retrospective review of 5 exemplar countries that made significant improvements in stunting found that nutritionsensitive strategies accounted for $50 \%$ of the total stunting reduction. ${ }^{42}$ Despite compelling ecological evidence, nutrition-sensitive interventions have not consistently shown improvements in linear growth in randomized controlled trials. Future research is urgently needed in this area. ${ }^{21}$

Our study supports the emerging criticism of SUN's emphasis on technical solutions to address stunting. An independent review of the SUN

\section{The current study supports the emerging criticism of SUN's emphasis on technical solutions to address stunting.}


movement has acknowledged that (1) there is limited evidence that SUN has improved nutrition outcomes of member countries, (2) some countries including Guatemala that closely adhere to SUN have not observed meaningful improvements in stunting, and (3) SUN's standardized approach does not sufficiently account for local country factors. ${ }^{48}$ Other critics have argued that SUN emphasizes short-term technical solutions with limited consideration of the structural causes of stunting. ${ }^{49}$ In this view, even SUN's nutritionsensitive interventions primarily serve to benefit commercial food systems that disrupt indigenous food cultures, decrease confidence in local foods, and reduce biodiversity. ${ }^{49}$ In Guatemala and elsewhere, critics of SUN have pointed out conflicts of interest, ${ }^{50}$ human-rights concerns among adolescent mothers, ${ }^{51,52}$ and detachment from communities affected by malnutrition. ${ }^{49}$ Although our study does not address these broader critiques, our results buttress criticisms against SUN's emphasis on narrow technical interventions and call for increased focus on strategies that address the social determinants that give rise to stunting.

With respect to our study's implications in Guatemala, a principal target of the Great Crusade is a $7 \%$ reduction in stunting prevalence from 2020 to 2024. Our study suggests that this target is very ambitious and unlikely to be achieved solely based on scaling-up interventions recommended by SUN and outlined in the Great Crusade. According to our projections, even aspirational levels of coverage would only reduce stunting prevalence by $-2.2 \%(95 \% \mathrm{CI}=-1.6 \%,-3.0 \%)$ in $2024,-0.6 \%$ per year. Previous reviews of countries that made significant strides in improving stunting have shown that per year reductions in stunting greater than $1 \%$ are possible. ${ }^{46,53}$ The previous Guatemalan national nutrition policies from 2012 to $2016^{11}$ and from 2016 to $2020^{12}$ were also unable to reach targets of a $10 \%$ absolute reduction in stunting. Importantly, while the Great Crusade confers only a small absolute reduction in stunting prevalence in our models, we also project that the policy would avert over 42,000 total stunting cases from 2020 to 2024 and 217,000 total cases from 2020 to 2030. This absolute number of cases averted may be viewed as substantial by policy makers and nutrition stakeholders in a country with a total population of 16.9 million people.

We found dramatic differences in impact among interventions recommended by SUN and included in the Great Crusade. Complementary feeding and basic sanitation contribute to more than half of the stunting cases averted in most of our models. In LiST, complementary feeding is defined as the percentage of mothers who received counseling on complementary feeding practices and continuing breastfeeding after 6 months. ${ }^{54}$ Complementary feeding has a particularly large impact in the aspirational models, and we estimate that increasing complementary feeding intervention coverage to $90 \%$ by 2024 would avert 245,000 total stunting cases from 2020 to 2030. After complementary feeding, the intervention contributing the greatest impact on stunting reduction between the Great Crusade and aspirational models was breastfeeding promotion. Interventions such as complementary feeding and breastfeeding promotion are "double-duty actions" that also may confer beneficial impacts on obesity and other diet-related noncommunicable diseases. ${ }^{55}$ Notably, some interventions such as multiple micronutrient supplementation in pregnancy, rotavirus vaccine, and vitamin A supplementation had minimal impact on stunting due to high levels of coverage at baseline, small effect sizes, or limited need. Previous research has suggested an association between family planning and child stunting, ${ }^{37}$ but our models found that decreasing fertility risks had a very small impact on stunting. Our results suggest that efforts to reduce stunting should focus resources on scaling up coverage of specific interventions (complementary feeding, basic sanitation, and breastfeeding) over others (multiple micronutrient supplementation in pregnancy, rotavirus vaccine, and vitamin A supplementation) during the Great Crusade's implementation phase.

Our study makes a useful methodological contribution to the broader literature that uses LiST and other modeling tools to project maternal and child health outcomes. To our knowledge, this is the first study that uses LiST to project the impact of a national health policy as the policy is launched.

The strengths of this study include our choice of a well-established modeling tool (LiST) and our detailed assessments of uncertainty. Policy analyses often report exact predictions without assessments of uncertainty, a practice criticized in the literature as "incredible certitude." ${ }^{56}$ We agree that uncertainty should be transparently and appropriately communicated in policy analyses including maternal and child health models such as LiST. ${ }^{57}$ We depict the uncertainty of our models in Figures 2 and 3 where greater changes in intervention coverage and time were accompanied by larger uncertainty. We also updated default inputs with new and nonpublic data sources. Finally, we addressed the gap between the last Demographic 
and Health Survey in Guatemala (2014-2015) and the first year of our projection (2020) by estimating baseline 2020 inputs using a methodology from the literature.

\section{Limitations}

Our study has several limitations. First, our study assesses only a single country, Guatemala. We justify our focus on Guatemala given the country's unique position of extraordinary stunting prevalence and sustained commitment to SUN. Furthermore, country case studies have a rich tradition in informing global policy within the maternal and child health field. ${ }^{46}$ Second, LiST was designed to estimate the impact of evidence-based interventions with known effect sizes. We are unable to estimate the impact of nutrition-sensitive interventions in the Great Crusade that have uncertain effect sizes such as education and conditional-cash transfer programs. We also are unable to model complex secular trends in stunting prevalence in Guatemala that are likely to be occurring as the country is becoming wealthier and more educated. Third, our study focuses on linear growth-represented by stunting - as a central metric of early child health. However, there has been increasing criticism of the causal assumptions between linear growth in children and long-term developmental outcomes. ${ }^{58}$ Pioneering studies in Jamaica ${ }^{59-61}$ and meta-analyses ${ }^{62,63}$ show that early childhood education and stimulation interventions can improve child development without improving growth. In Guatemala, community-based interventions targeting the determinants of child development (and not solely growth) are important but are not considered in our study. ${ }^{64,65}$

A final limitation involves the uncertainty of nutrition policy in Guatemala during the COVID19 pandemic. The Great Crusade was published in February 2020 before the first documented case of COVID-19 in Guatemala. Undoubtedly, COVID19 will have direct and indirect effects on nutrition in Guatemala. Reports of increased food insecurity and acute malnutrition have emerged, ${ }^{66,67}$ while funds destined for nutrition programs are being rerouted to fight COVID-19. ${ }^{68}$ We chose not to consider COVID-19 in our analysis for 3 reasons: (1) our primary goal was to assess the Great Crusade as a policy document, (2) the lack of currently available COVID-19 data in Guatemala make any long-term projections impractical, and (3) modeling health system shocks in LiST requires different modeling techniques and assumptions. ${ }^{69}$

\section{CONCLUSION}

This modeling study using LiST found that that the most recent Guatemalan national nutrition policy, the Great Crusade, will have difficulty achieving 2024 national targets or 2030 SDG targets solely based on increases in intervention coverage. Our results show the limitations of technical solutions to nutrition put forth by the international nutrition community. Despite more than a decade of political commitment on the issue of nutrition, Guatemala may continue to have exceptionally high prevalence of stunting over the coming decade. We recommend the prioritization of interventions that are projected to confer the largest impact such as complementary feeding, breastfeeding, and basic sanitation. Policies and strategies are needed to address the broader social structures that predispose children to stunting.

Author contributions: ST and DF designed the study and executed the analysis. AC, GA, MM, MFK, BJ, and PR all made contributions to the study design, data collection, and data analysis. All authors contributed to the production of the manuscript.

Competing interests: None declared.

\section{REFERENCES}

1. Development Initiatives. 2020 Global Nutrition Report: Action on Equity to End Malnutrition. Development Initiatives; 2020. Accessed August 27, 2021. https://globalnutritionreport.org/reports/2020global-nutrition-report/

2. Black RE, Victora CG, Walker SP, et al.; Maternal and Child Nutrition Study Group. Maternal and child undernutrition and overweight in low-income and middle-income countries. Lancet. 2013;382(9890):427-451. CrossRef. Medline

3. Grantham-McGregor S, Cheung YB, Cueto S, Glewwe P, Richter L, Strupp B; International Child Development Steering Group. Developmental potential in the first 5 years for children in developing countries. Lancet. 2007;369(9555):60-70. CrossRef. Medline

4. Ford ND, Behrman JR, Hoddinott JF, et al. Exposure to improved nutrition from conception to age 2 years and adult cardiometabolic disease risk: a modelling study. Lancet Glob Health. 2018;6(8): e875-e884. CrossRef. Medline

5. Adair LS, Fall CHD, Osmond C, et al.; COHORTS group. Associations of linear growth and relative weight gain during early life with adult health and human capital in countries of low and middle income: findings from five birth cohort studies. Lancet. 2013;382 (9891):525-534. CrossRef. Medline

6. DeBoer MD, Lima AAM, Oría RB, et al. Early childhood growth failure and the developmental origins of adult disease: do enteric infections and malnutrition increase risk for the metabolic syndrome? Nutr Rev. 2012;70(1 1):642-653. CrossRef. Medline

7. De Lucia Rolfe E, de França GVA, Vianna CA, et al. Associations of stunting in early childhood with cardiometabolic risk factors in adulthood. PLoS One. 2018;13(4):e0192196. CrossRef. Medline

8. Scaling Up Nutrition. An Introduction to the Scaling Up Nutrition Movement. Scaling Up Nutrition; 2014. Accessed August 27, 2021. http://scalingupnutrition.org/wp-content/uploads/2015/06/ Orange_Internal_InOutline_ENG_20140415_web.pdf 
9. The vision and principles of SUN. Scaling Up Nutrition. Accessed August 27, 2021. https://scalingupnutrition.org/about-sun/thevision-and-principles-of-sun/

10. Gobierno de Guatemala. Secretaría de Seguridad Alimentaria y Nutricional. Accessed September 9, 2020. http://www.siinsan.gob. $\mathrm{gt} /$ siinsan/wp-content/uploads/Ley_de-SAN.pdf

11. Gobierno de Guatemala. El Plan Del Pacto Hambre Cero. 2012. Accessed August 27, 2021. https://www.transparencia.gob.gt/ wp-content/uploads/2017/07/INF-2012-002.pdf

12. Secretaría de Seguridad Alimentaria y Nutricional. Estrategia Nacional Para La Prevención de La Desnutrición Crónica $2016-$ 2020. Comisión Nacional para la Reducción de la Desnutrición Crónica; 2016. Accessed August 27, 2021. http://www. sesan.gob. gt/wordpress/wp-content/uploads/2017/07/Estrategia-para-laPrevencion-de-la-Desnutricion-Cronica.pdf

13. Gobierno de Guatemala. Gran Cruzada Nacional Por La Nutrición 2020. Accessed August 27, 2021. http://www.sesan.gob.gt/ wordpress/wp-content/uploads/2020/04/Documento-tecnicoGran-Cruzada-Nacional_17HD.pdf

14. Mokoro Limited. Independent Comprehensive Evaluation of the Scaling Up Nutrition Movement: Final Report-Main Report and Annexe. Mokoro Limited; 2015. Accessed August 27, 2021. http:// scalingupnutrition.org/wp-content/uploads/2015/05/SUN_ICE_ FullReport-All(1-5-15).pdf

15. HANCl Global. Hunger and Nutrition Commitment Index. $\mathrm{HANCl}$; 2020. Accessed August 27, 2021. http://www.hancindex.org/ hanci/

16. Kinyoki DK, Osgood-Zimmerman AE, Pickering BV, et al.; Local Burden of Disease Child Growth Failure Collaborators. Mapping child growth failure across low- and middle-income countries. Nature. 2020;577(7789):231-234. CrossRef. Medline

17. Ministerio de Salud Pública y Asistencia Social (MSPAS), Instituto Nacional de Estadística (INE), Secretaría de Planificación y Programación de la Presidencia (Segeplán). Encuesta Nacional de Salud Materno Infantil 2014-2015. MSPAS, INE, Segeplán; 2017. Accessed August 27, 2021. https://www.ine.gob.gt/images/ 2017/encuestas/ensmi2014_2015.pdf

18. Mazariegos M, Kroker-Lobos MF, Ramírez-Zea M. Socio-economic and ethnic disparities of malnutrition in all its forms in Guatemala. Public Health Nutr. 2020;23(S1):s68-s76. CrossRef. Medline

19. Gatica-Domínguez G, Victora C, Barros AJD. Ethnic inequalities and trends in stunting prevalence among Guatemalan children: an analysis using national health surveys 1995-2014. Int J Equity Health. 2019;18(1):110. CrossRef. Medline

20. United Nations Children's Fund (UNICEF). Improving Child Nutrition: The Achievable Imperative for Global Progress. UNICEF; 2013. Accessed August 27, 2021. https://data.unicef.org/ resources/improving-child-nutrition-the-achievable-imperative-forglobal-progress/

21. Ruel MT, Alderman H; Maternal and Child Nutrition Study Group. Nutrition-sensitive interventions and programmes: how can they help to accelerate progress in improving maternal and child nutrition? Lancet. 2013;382(9891):536-551. CrossRef. Medline

22. International Food Policy Research Institute (IFPRI). Informe Final de Evaluación de Impacto Del Plan Del Pacto Hambre Cero. IFPRI; 2016. Accessed August 27, 2021. http://www.siinsan.gob.gt/ siinsan/wp-content/uploads/Informe-Final-Evaluacion-ImpactoPPHO.pdf

23. Bhutta ZA, Das JK, Rizvi A, et al.; Lancet Nutrition Interventions Review Group, the Maternal and Child Nutrition Study Group. Evidence-based interventions for improvement of maternal and child nutrition: what can be done and at what cost? Lancet. 2013;382 (9890):452-477. CrossRef. Medline

24. Fundación para el Desarrollo de Guatemala (FUNDESA). Alianza por la Nutrición. Informe 6to. Monitoreo de la Ventana de los Mil
Días: Informe con los resultados completos del análisis cuantitativo de las distintas bases de datos colectadas. FUNDESA; 2019. Accessed August 27, 2021. https://www.fundesa.org.gt/content/ files/publicaciones/20196to_Informe_final_6to_Monitoreo_ Ventana_Mil_Dias___FUNDESA-APN-comprimido.pdf

25. Walker N, Tam Y, Friberg IK. Overview of the lives saved tool (LiST). BMC Public Health. 2013;13(Suppl 3):S1. CrossRef. Medline

26. Garnett GP, Cousens S, Hallett TB, Steketee R, Walker N. Mathematical models in the evaluation of health programmes. Lancet. 2011;378(9790):515-525. CrossRef. Medline

27. Cousens S, Perin J, Christian P, et al. Modelling stunting in LiST: the effect of applying smoothing to linear growth data. BMC Public Health. 2017;17(S4)(Suppl 4):778. CrossRef. Medline

28. Clermont A, Walker N. Nutrition Interventions in the Lives Saved Tool (LiST). J Nutr. 2017; 147(11):2132S-2140S. CrossRef. Medline

29. Alderman H, Nguyen PH, Menon P. Progress in reducing child mortality and stunting in India: an application of the Lives Saved Tool. Health Policy Plan. 2019;34(9):667-675. CrossRef. Medline

30. Mishra NR, Mohanty SK, Mittra D, Shah M, Meitei WB. Projecting stunting and wasting under alternative scenarios in Odisha, India, 2015-2030: a Lives Saved Tool (LiST)-based approach. BMJ Open. 2019;9(5):e028681. CrossRef. Medline

31. The Lives Saved Tool. LiST sensitivity and uncertainty description of methods 042820 .

32. LiST in peer-reviewed journals. The Lives Saved Tool. Accessed August 27, 2021. https://wmw.livessavedtool.org/list-inpeerreviewed-journals

33. Black RE, Levin C, Walker N, Chou D, Liu L, Temmerman M. Reproductive, maternal, newborn, and child health: key messages from Disease Control Priorities 3rd Edition. Lancet. 2016;388 (10061):2811-2824. CrossRef. Medline

34. About LiST. The Lives Saved Tool. Accessed August 27, 2021. https://www.livessavedtool.org/about-1

35. WHO Multicentre Growth Reference Study Group. WHO Child Growth Standards based on length/height, weight and age. Acta Paediatr Suppl. 2006;450:76-85. CrossRef. Medline

36. Júnior JM, Cane RM, Gonçalves MP, et al. Projecting the lives saved by continuing the historical scale-up of child and maternal health interventions in Mozambique until 2030. J Glob Health. 2019;9 (1):01 1 102. CrossRef. Medline

37. Flood D, Petersen A, Martinez B, Chary A, Austad K, Rohloff P. Associations between contraception and stunting in Guatemala: secondary analysis of the 2014-2015 Demographic and Health Survey. BMJ Paediatr Open. 2019;3(1):e000510. CrossRef. Medline

38. Fink G, Sudfeld CR, Danaei G, Ezzati M, Fawzi WW. Scaling-up access to family planning may improve linear growth and child development in low and middle income countries. PLoS One. 2014;9 (7):e102391. CrossRef. Medline

39. Chou VB, Friberg IK, Christian M, Walker N, Perry HB. Expanding the population coverage of evidence-based interventions with community health workers to save the lives of mothers and children: an analysis of potential global impact using the Lives Saved Tool (LiST). J Glob Health. 2017;7(2):020401. CrossRef. Medline

40. Higgins-Steele A, Yousufi K, Sultana S, Ali AS, Varkey S. Ending preventable child deaths from pneumonia and diarrhoea in Afghanistan: an analysis of intervention coverage scenarios using the Lives Saved Tool. J Trop Med. 2017;2017:3120854. CrossRef. Medline

41. Open Science Framework (OSF). Simulating the impact of the Gran Cruzada using the Lives Saved Tool (LiST). OSF; 2020. Accessed August 27, 2021. https://osf.io/2nu87 
42. Bhutta ZA, Akseer N, Keats EC, et al. How countries can reduce child stunting at scale: lessons from exemplar countries. Am J Clin Nutr. 2020;112(Supplement_2):894S-904S. CrossRef. Medline

43. Panjwani A, Heidkamp R. Complementary feeding interventions have a small but significant impact on linear and ponderal growth of children in low- and middle-income countries: a systematic review and meta-analysis. J Nutr. 2017;147(11):jn243857. CrossRef. Medline

44. Stewart CP, lannotti L, Dewey KG, Michaelsen KF, Onyango AW. Contextualising complementary feeding in a broader framework for stunting prevention. Matern Child Nutr. 2013;9(Suppl 2):27-45. CrossRef. Medline

45. Hossain M, Choudhury N, Adib Binte Abdullah K, et al. Evidencebased approaches to childhood stunting in low and middle income countries: a systematic review. Arch Dis Child. 2017;102(10):903909. CrossRef. Medline

46. Huicho L, Segura ER, Huayanay-Espinoza CA, et al.; Peru Countdown Country Case Study Working Group. Child health and nutrition in Peru within an antipoverty political agenda: a Countdown to 2015 country case study. Lancet Glob Health. 2016;4(6):e414e426. CrossRef. Medline

47. Huicho L, Vidal-Cárdenas $E$, Akseer N, et al. Drivers of stunting reduction in Peru: a country case study. Am J Clin Nutr. 2020;1 12 (Suppl_2):816S-829S. CrossRef. Medline

48. Strategic Review of the Scaling Up Nutrition (SUN) Movement, 2019-2020. 2020. Accessed August 27, 2021. https:// scalingupnutrition.org/wp-content/uploads/2020/04/SUNStrategic-Review-Final-Report_ENG.pdf

49. Michéle L, Prato S, Rundall P, Valente F. When the SUN Casts a Shadow - The Human Rights Risks of Multi-Stakeholder Partnerships: The Case of Scaling up Nutrition (SUN). FIAN International, IBFAN, Society for International Development; 2019. Accessed August 27 2021. https://fian.org/files/files/WhenTheSunCastsAShadow_En. pdf

50. Lie AL. 'We are not a partnership' - constructing and contesting legitimacy of global public-private partnerships: the Scaling Up Nutrition (SUN) Movement. Globalizations. 2020;18(2):237-255. CrossRef

51. Flood D, Chary A, Colom A, Rohloff P. Adolescent rights and the "First 1,000 days" global nutrition movement: a view from Guatemala. Health Hum Rights. 2018;20(1):295-301. Medline

52. Colom A. Forced motherhood in Guatemala: an analysis of the Thousand Days Initiative. In: Chary A, Rohloff P, eds. Privatization and the New Medical Pluralism: Shifting Healthcare Landscapes in Maya Guatemala. Lexington Books; 2015:35-49.

53. Zanello G, Srinivasan CS, Shankar B. What explains Cambodia's success in reducing child stunting -2000-2014? PLoS One. 2016;11(9):e0162668. CrossRef. Medline

54. Avenir Health. Spectrum Manual: Spectrum System of Policy Models. Avenir Health; 2021. Accessed August 27, 2021. https:// avenirhealth.org/Download/Spectrum/Manuals/ SpectrumManualE.pdf

55. Hawkes C, Ruel MT, Salm L, Sinclair B, Branca F. Double-duty actions: seizing programme and policy opportunities to address malnutrition in all its forms. Lancet. 2020;395(10218):142-155. CrossRef. Medline
56. Manski CF. Communicating uncertainty in policy analysis. Proc Natl Acad Sci USA. 2019;1 16(16):7634-7641. CrossRef. Medline

57. Hodgins S. Modeling outputs can be valuable when uncertainty is appropriately acknowledged, but misleading when not. Glob Health Sci Pract. 2017;5(4):530-533. CrossRef. Medline

58. Leroy JL, Frongillo EA. Perspective: what does stunting really mean? A critical review of the evidence. Adv Nutr. 2019;10(2):196-204. CrossRef. Medline

59. Gertler P, Heckman J, Pinto R, et al. Labor market returns to an early childhood stimulation intervention in Jamaica. Science. 2014;344 (6187):998-1001. CrossRef. Medline

60. Walker SP, Chang SM, Vera-Hernández M, Grantham-McGregor $S$. Early childhood stimulation benefits adult competence and reduces violent behavior. Pediatrics. $2011 ; 127(5): 849-857$. CrossRef. Medline

61. Walker SP, Chang SM, Powell CA, Grantham-McGregor SM. Effects of early childhood psychosocial stimulation and nutritional supplementation on cognition and education in growth-stunted Jamaican children: prospective cohort study. Lancet. 2005;366(9499): 18041807. CrossRef. Medline

62. Aboud FE, Yousafzai AK. Global health and development in early childhood. Annu Rev Psychol. 2015;66(1):433-457. CrossRef. Medline

63. Prado EL, Larson LM, Cox K, Bettencourt K, Kubes JN, Shankar AH. Do effects of early life interventions on linear growth correspond to effects on neurobehavioural development? A systematic review and meta-analysis. Lancet Glob Health. 2019;7(10):e1398-e1413. CrossRef. Medline

64. Durao S, Visser ME, Ramokolo V, et al. Community-level interventions for improving access to food in low- and middle-income countries. Cochrane Database Syst Rev. 2020;7(7):CD01 1504. CrossRef. Medline

65. Engle PL, Fernald LCH, Alderman H, et al.; Global Child Development Steering Group. Strategies for reducing inequalities and improving developmental outcomes for young children in lowincome and middle-income countries. Lancet. $2011 ; 378$ (9799):1339-1353. CrossRef. Medline

66. La COVID-19 duplica el número de personas sin alimentos en Guatemala. Acción Contra El Hambre. June 15, 2020. Accessed August 27, 2021. https://www.accioncontraelhambre.org/es/tecontamos/actualidad/la-covid-19-duplica-el-numero-de-personassin-alimentos-en-guatemala

67. Lucía Ola A. Crisis del coronavirus: Desnutrición y el hambre que agobia a varias familias del Corredor Seco. Prensa Libre. May 4, 2020. Accessed August 27, 2021. https://www. prensalibre.com/ guatemala/comunitario/antes-del-coronavirus-en-el-corredorseco-la-gente-lucha-contra-el-hambre/

68. Lucía Ola A. Salud reduce presupuesto a programas contra la desnutrición y traslada los fondos al combate del covid-19. Prensa Libre. June 23, 2020. Accessed August 27, 2021. https://www. prensalibre.com/guatemala/comunitario/salud-reducepresupuesto-a-programas-contra-la-desnutricion-y-traslada-losfondos-al-combate-del-covid-19/

69. Roberton T, Carter ED, Chou VB, et al. Early estimates of the indirect effects of the COVID-19 pandemic on maternal and child mortality in low-income and middle-income countries: a modelling study. Lancet Glob Health. 2020;8(7):e901-e908. CrossRef. Medline

\section{En Español}

Proyección del Impacto de La Política Nutricional para Mejorar el Retraso del Crecimiento en Niños: Un Estudio de Caso en Guatemala Usando la Herramienta Lives Saved Tool 


\section{Hallazgos Clave}

- La ampliación de la cobertura de las intervenciones nutricionales basadas en evidencia, recomendadas por la comunidad internacional, solamente contribuirán a una pequeña mejora en el retraso del crecimiento de los niños en Guatemala, y es muy poco probable que se cumpla la ambiciosa meta nacional fijada para el 2024 o con los ODS para el 2030.

- Nuestros resultados apoyan un enfoque para aumentar las estrategias que abordan los determinantes sociales del retraso del crecimiento en lugar de un enfoque estrecho enfocado en intervenciones específicas de nutrición.

Implicaciones Clave

- Es poco probable que se logren grandes mejoras en el retraso del crecimiento de los niños en algunos países con alta prevalencia como Guatemala, solamente con ampliar la cobertura de las intervenciones específicas de nutrición.

- Se necesitan políticas nutricionales y sociales multisectoriales para abordar los determinantes estructurales del retraso del crecimiento.

\section{RESUMEN}

Contexto: El retraso del crecimiento en niños es un asunto crítico de salud a nivel mundial. Guatemala tiene una de las prevalencias más altas de retraso del crecimiento en niños en el mundo, a pesar de su compromiso sostenido con las intervenciones nutricionales respaldadas por el Movimiento para el Fomento a la Nutrición (SUN por sus siglas en inglés). Nuestro objetivo fue utilizar a Guatemala como un estudio de caso y proyectar el impacto de la política nacional de nutrición recientemente publicada, la Gran Cruzada por la Nutrición, que es consistente con los principios de SUN.

Métodos:Usamos la herramienta Lives Saved Tool (LiST) para proyectar el impacto de ampliar la cobertura de las intervenciones nutricionales propuestas en la Gran Cruzada por la Nutrición y recomendadas por SUN. Nuestros resultados fueron cambios en la prevalencia de retraso del crecimiento, el número de casos evitados de retraso del crecimiento, y el número de casos evitados de retraso del crecimiento por cada intervención en niños menores de 5 años de edad del 2020 al 2030. Consideramos cuatro escenarios: (1) cobertura de las intervenciones basada en las tendencias históricas, (2) metas de cobertura de la Gran Cruzada por la Nutrición alcanzadas, (3) metas de cobertura de la Gran Cruzada por la Nutrición alcanzadas al disminuir la tasa de fertilidad y (4) cobertura ampliada a un nivel aspiracional.

Resultados: Todos los escenarios resultaron en reducciones modestas de la prevalencia de retraso del crecimiento. En 2024, estimamos que la prevalencia de retraso del crecimiento cambiaría en $-0.1 \%$ (intervalo de confianza $95 \%[\mathrm{IC}]=0.0 \%, 0.2 \%$ ) si las tendencias históricas continúan $-1.1 \%$ (IC 95\% $=-0.8 \%,-1.5 \%$ ) en el escenario de la Gran Cruzada por la Nutrición, y $-2.2 \%$ (IC $95 \%=-1.6 \%,-3.0 \%$ ) en el escenario aspiracional. En 2030 , proyectamos una prevalencia de retraso del crecimiento de $-0.4 \%(95 \% \mathrm{Cl}=-0.2 \%,-0.8 \%)$ y $-3.7 \%(95 \% \mathrm{Cl}=-2.8 \%,-5.1 \%)$ en el escenario de tendencias históricas y en el escenario aspiracional, respectivamente. La alimentación complementaria, saneamiento y la lactancia materna fueron las intervenciones de mayor impacto en todos los modelos.

Conclusiones: Es poco probable que la reducción en la prevalencia de retraso del crecimiento propuesto en Guatemala sea lograda solamente con el aumento de la cobertura de las intervenciones. Nuestros resultados muestran las limitaciones de los paradigmas actuales recomendados por la comunidad internacional de nutrición. Se necesitan políticas y estrategias que aborden los determinantes estructurales del retraso del crecimiento.

\section{Peer Reviewed}

Received: September 22, 2020; Accepted: August 10, 2021; First published online: October 26, 2021.

Cite this article as: Tschida S, Cordon A, Asturias G, et al. Projecting the impact of nutrition policy to improve child stunting: a case study in Guatemala using the Lives Saved Tool. Glob Health Sci Pract. 2021;9(4):752-764. https://doi.org/10.9745/GHSP-D-20-00585

(c) Tschida et al. This is an open-access article distributed under the terms of the Creative Commons Attribution 4.0 International License (CC BY 4.0), which permits unrestricted use, distribution, and reproduction in any medium, provided the original author and source are properly cited. To view a copy of the license, visit https://creativecommons. org/licenses/by/4.0/. When linking to this article, please use the following permanent link: https:// doi.org/10.9745/GHSP-D-20-00585 